\title{
PWE-005 COMPLICATION RATES OF ENDOSCOPIC POLYPECTOMY IN RELATION TO POLYP CHARACTERISTICS AND TECHNIOUES
}

doi:10.1136/gut.2011.239301.268

W K Choo,* J Subhani ${ }^{1}$ Basildon and Thurrock University Hospital NHS, Basildon, UK

Introduction Endoscopic polypectomy (EP) could reduce colorectal cancer incidence by $76-90 \%$. Quoted rates of major complications in EPs were low, often less than $1 \%$. We aimed to examine our complication rates in relation to the characteristics of polyps removed and techniques employed.

Methods We retrospectively reviewed 2106 EPs performed on 1252 consecutive patients over a 3.5-year period between January 2006 and June 2009. EP techniques and polyp morphology, site and size were examined. EP data were matched with data on readmissions post-endoscopy. Serious complications were defined as events leading to readmission within a 14 -day period. $\chi^{2}$-test and Fishers Exact Analysis were used in significance testing.

Results Majority of our EPs were done with colonoscopy (94\%) while 6\% were done with flexible sigmoidoscopy. Thirteen patients or $23(1.1 \%)$ polypectomies had complications within 14 days. None of our complications involved perforation, $10(0.47 \%)$ had bleeding and $4(0.19 \%)$ had postpolypectomy syndromes. Our bleeding rate was 1:211, lower than the national standard of 1:100. No deaths were reported within the study period.

Majority of polyps removed were sessile in morphology (77\%) with another $23 \%$ being pedunculated. Over $80 \%$ of polyps resected were $10 \mathrm{~mm}$ or less. The number of polyps removed fell with increasing size. Only $2 \%$ of polyps removed were larger than $30 \mathrm{~mm}$, largest being $80 \mathrm{~mm}$ (2 polyps). Complication rates rose from $1 \%$ in the smallest group $(1-10 \mathrm{~mm})$ to $4.9 \%$ in the largest $(>31 \mathrm{~mm})$ but the rise was not statistically significant $(\mathrm{p}=0.067)$.

We performed more EPs in the descending colon, sigmoid colon and rectum (70\%) than in the rest of the colon but found fewer complications in these groups compared to ascending and transverse colon polypectomies $(p=0.002)$. The latter groups had a higher tendency of developing post-polypectomy syndrome and bleeding.

We performed $1163(55 \%)$ snares, 783 (37\%) hot biopsies and $164(8 \%)$ endoscopy mucosal resections (EMR). Complication rates in snare polypectomies were not significantly different from that of hot biopsies $(p=0.64)$. However, EMR had significantly more complications compared to snares $(p=0.045)$ and hot biopsies $(p=0.026)$.

Conclusion We achieved lower bleeding rates than that published nationally. Hot biopsy did not carry a higher risk although EMR did. Polyp size was an important risk factor although statistical significance was not met. Ascending and transverse colon polypectomies carried the highest risks of complications. Patients should be made aware of this risk prior 
to their procedure. We would include the rates of minor complications in a longer follow-up in future studies.

Competing interests None.

Keywords EMR, hot biopsy, polypectomy, Snare. 